\title{
Journal of Plant Sciences
}

2014; 2(6): 282-292

Published online December 15, 2014 (http://www.sciencepublishinggroup.com/j/jps) doi: $10.11648 /$ j.jps.20140206.14

\section{'Flower' of Magnolia grandiflora is not flower and what about 'basal angiosperms'}

\author{
Valentin Krassilov ${ }^{*}$, Sophia Barinova \\ Institute of Evolution, University of Haifa, Mount Carmel, Haifa 31905, Israel
}

Email address:

krassilo@research.haifa.ac.il (V. Krassilov),vakrassilov@gmail.com (V. Krassilov)

\section{To cite this article:}

Valentin Krassilov, Sophia Barinova. 'Flower' of Magnolia Grandiflora is not Flower and What about 'Basal Angiosperms'. Journal of Plant Sciences. Vol. 2, No. 6, 2014, pp. 282-292. doi: 10.11648/j.jps.20140206.14

\begin{abstract}
Gynoecial morphology of Magnolia grandiflora is revised, with 'follicles' reinterpreted as condensed branching systems forming a flower-like syncupulate infructescence ('secondary flower). Flowers appear on the main axis in the axils or on basal ramifications of gynoecial paracladia, those developing into fruits being incased by glandular calyptras, commonly perceived as seeds. Fruit wall is formed of zygomorphic corolla tube with persistent calyx and petaloid tepals, containing a solitary inverted seed in the fertile locule, with analogies in diverse 'eudicots'. These findings imply a reconsideration of 'basal angiosperms'.
\end{abstract}

Keywords: Plant Morphology, Plant Evolution, Flowering Plants, Angiosperm Phylogeny, Angiosperm Paleobotany

\section{Introduction}

Magnolia in flower is a splendid sight deservedly appreciated as emblematic for flowering plants. Magnoliophyta is widely accepted by contemporary botanists as taxonomic designation, supposedly a phylum of plant kingdom. The family Magnoliaceae is firmly established among the 'basal angiosperms' or 'paleodicots' that supposedly gave rise to the more advanced 'eudicots' as well as monocots. In a somewhat different arrangement, the magnoliids are 'mesangiosperms', perhaps next basal to the ANITA (or ANA) grade of molecular phylogeny. Yet the idea of perfect solitary flower as a basal condition is derived from contemplating Magnolia mainly, and the esthetic, as well as ethic implication is that simple is beautiful and most instructive.

We say 'contemplation' rather than study, because, as follows from our results. Magnolia grandiflora, the publicly most familiar species of the genus is misunderstood. The critical feature of its reproductive morphology is the so called seed that we interpret as fruit (anthocarp) with persistent floral parts. Their protective structures, conventionally described as follicles, are here interpreted as cupules derived from a branching system. Their woody carcass looks like a miniature Christmas tree with a stout axis and bushy branches, but also reminds the Roman Coliseum in being formed of ascending series of arches, with sophisticate ramifications beneath and microscopic mites busy on them. Our general impression is that beautiful is not simple (Fig. 1).

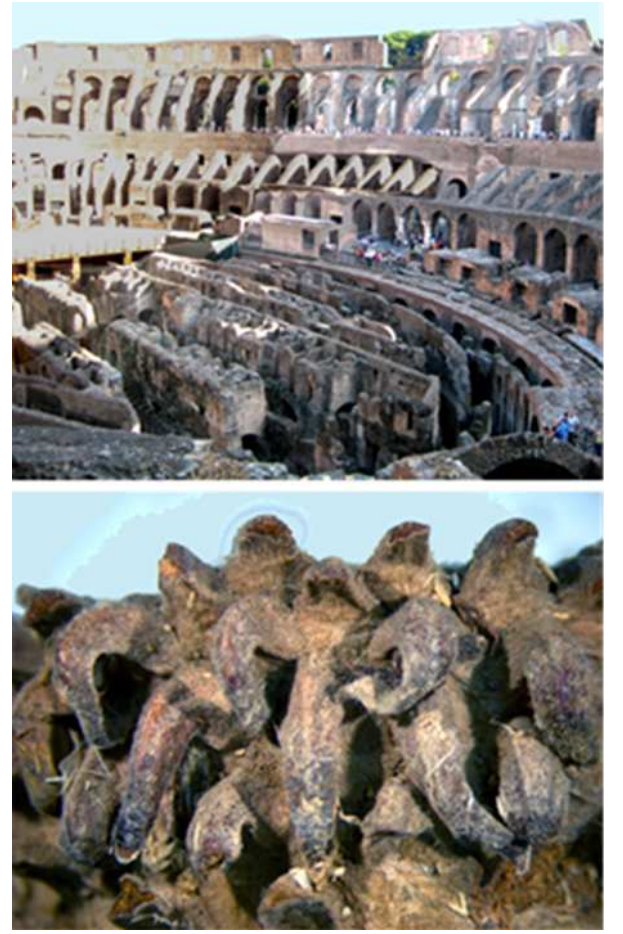

Figure 1. The gynoecium architecture in Magnolia grandiflora is like Roman Coliseum with its lofty arcades over the underground machinery, but also comparable with acorn cupule. 


\section{Material and Methods}

We picked up a few fruits in the garden and removed pulpy parts, revealing the woody carcass beneath. Otherwise the techniques and equipment are as in [1].

Because our interpretation of gynoecial structures in $M$. grandiflora is unlike the traditional one, we use different designations giving the traditional ones in inverted comas. Thus, fruit ('seed') means fruit traditionally described as seed. This way it may be easier for the reader to switch from the old concept of a 'solitary flower' to the new one of a compound inflorescence or 'secondary flower' (we suspect that the phenomenon is too widespread for 'pseudoflower' being a proper designations).

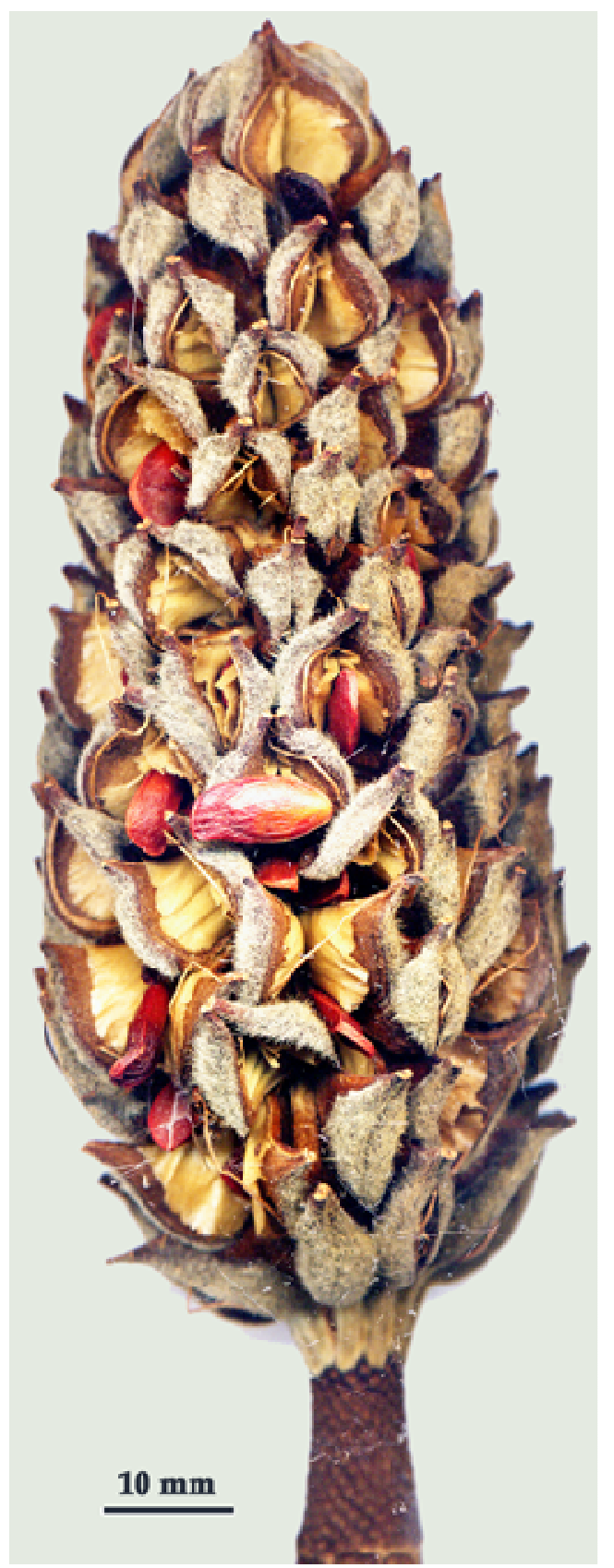

Figure 2. Magnolia grandiflora 'fruit' of partly open 'follicles'

\section{Results}

Externally, the 'fruit' of M. grandiflora shows spiral series of gibbous pulpy lumps vertically traversed with a median groove (the 'abaxial suture of a follicle'), and terminated with a shortly stalked bifid protuberance with recurred exostigmatic arms ('sigma'). Forced apart or naturally opened, the 'follicles' show a leathery inner wall ('endocarp') easily detachable from the fleshy hirsute outer wall ('pericarp') and enclosing one or two brightly red 'seeds' (Figs. 2, 3).
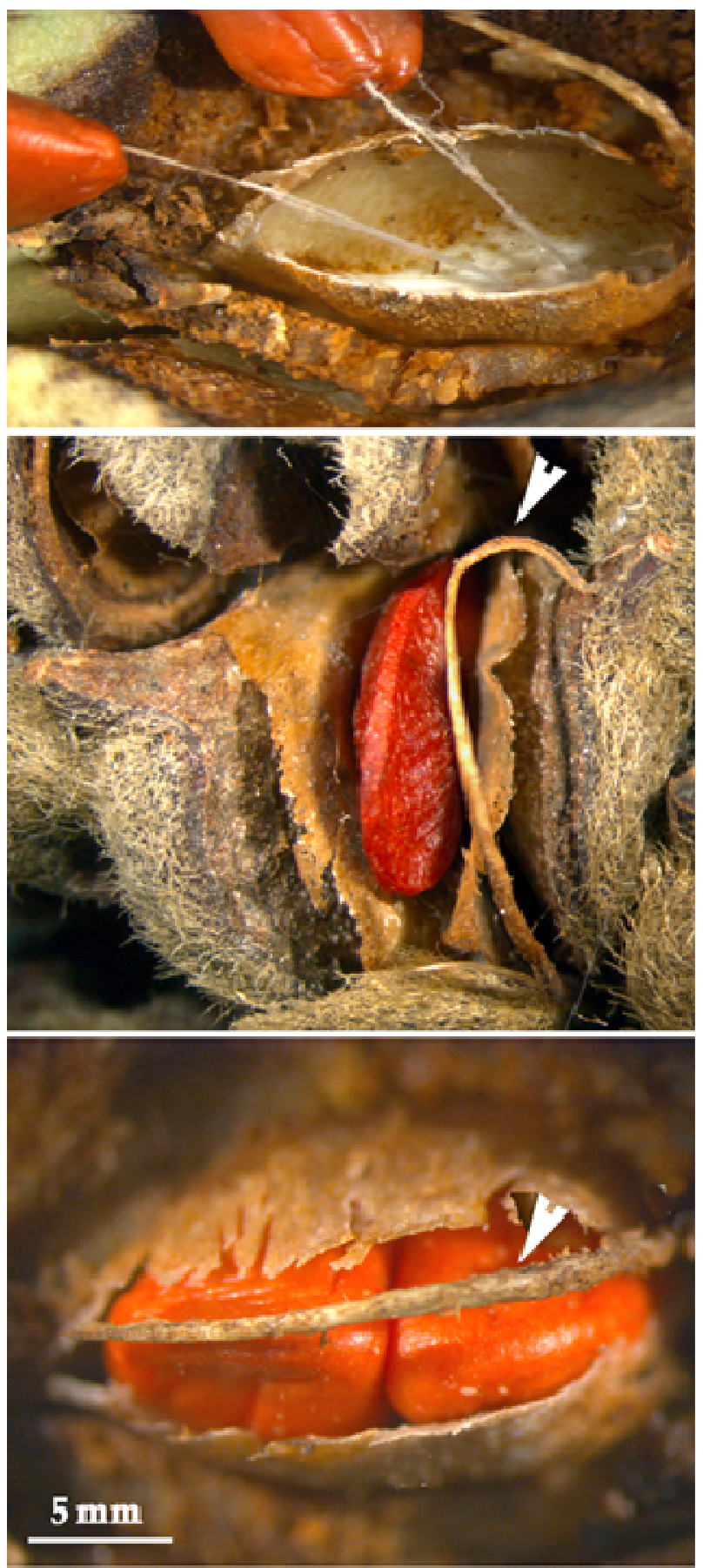

Figure 3. 'Follicles' showing red 'seeds' and a cord-like free branch inside adjoining the 'style' (arrowhead). 
In dehiscent 'fruits', the 'seeds' hang out on slender, but fairly durable filaments of interwoven spiral fibers, which is somewhat unusual, but the rest seem compatible with the traditional 'polyfollicle' interpretation. However, open 'follicles' show a cord-like free axis traversing the interior cavity along the abaxial groove and arching toward the style (Fig. 3). This entirely unusual feature is supposedly related to a peculiar pollination mode, but its morphological interpretation requires a closer look at the woody carcass of the fruit (Figs. 4, 5).

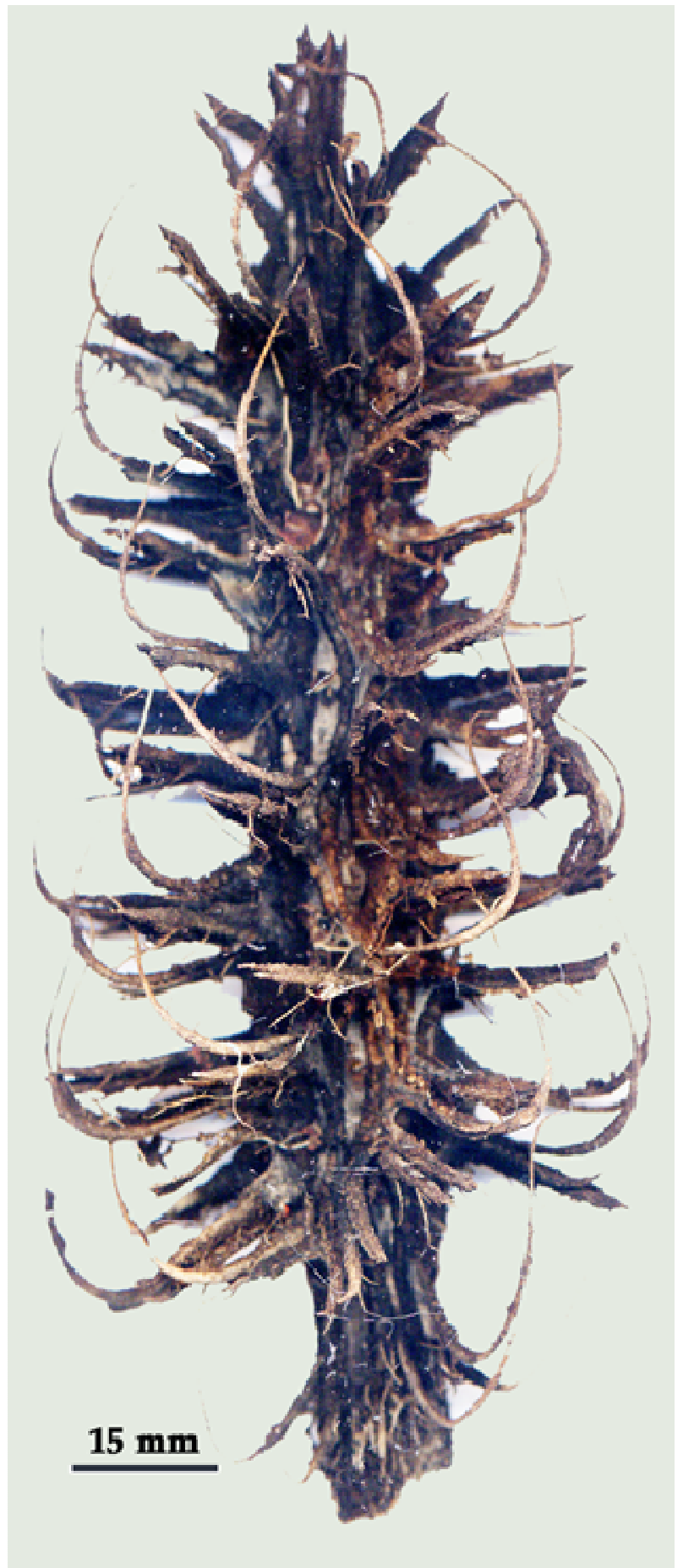

Figure 4. Woody carcass of the 'fruit' betraying a complex branching system.
Longitudinally split, the axis shows parallel bundles ('steles') in warty sheaths (Fig. 5). Although this study concerns the gynoecial structure, it is advisable to look at its peduncle ('pedicel') where the cortex is peeled off. A transverse section might give an impression of 'atactostele', but perceived three dimensionally the peduncle appears like a brushwood of slender twigs bearing prominent sclerified buds. At the base of it, confluent buds form imbricate sclerotic lamellae, irregularly lobed as in Fig. 6. As will be shown later in the paper, their appearance in the peduncle suggests incipient flowering at this level already.

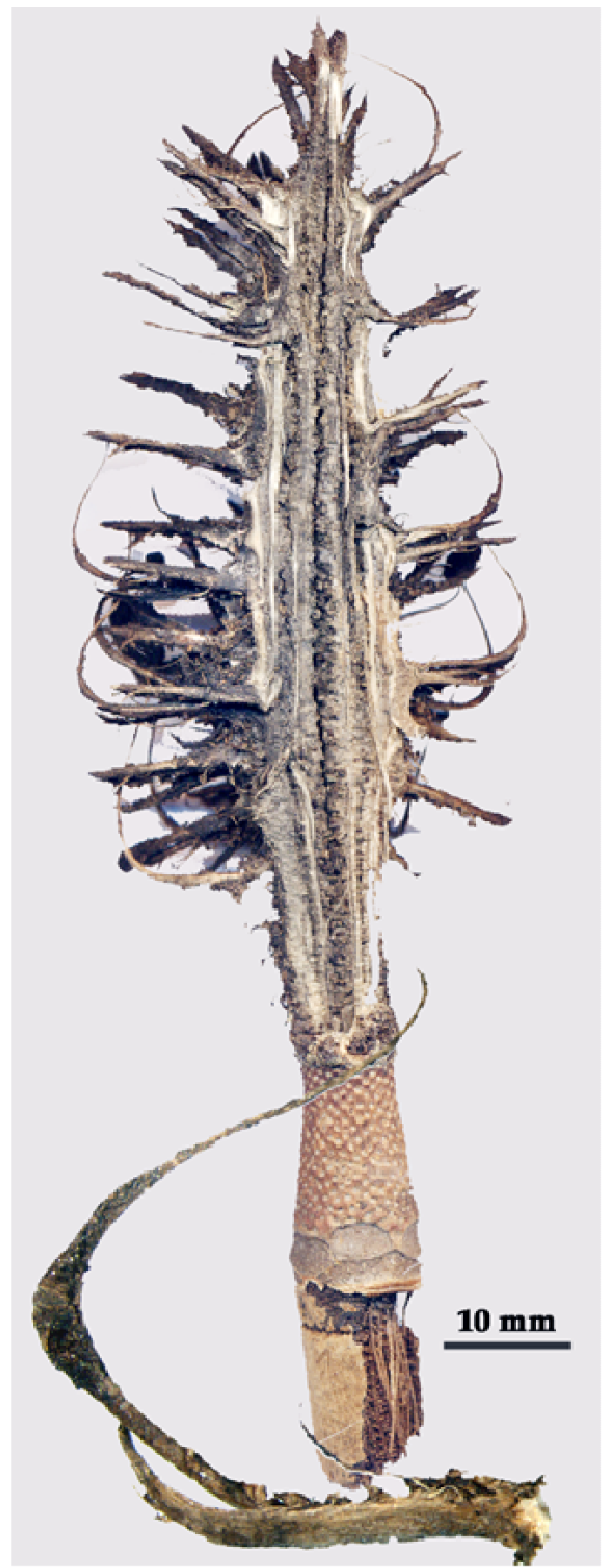

Figure 5. Split 'fruit' with axis showing parallel steles deviating as lateral paracladia interconnected with the cord-like offshoots. 
In the gynoecial zone, the robust lateral branches or paracladia depart from the peripheral stele bundles, spreading at the increasingly acute angle distally. They are clustered or paired, with the pairs parallel or somewhat divergent, longest in the middle of the axis, about $1.5 \mathrm{~mm}$ thick, with a warty sheath of stellate sclerites and with two rows of tuberous lateral buds, giving off slender second order plagiotropic branches, in turn ramified. A series of arches is formed this way flanked by the parallel series on both sides; a closed branching system supporting a syncopulate fruiting structure.
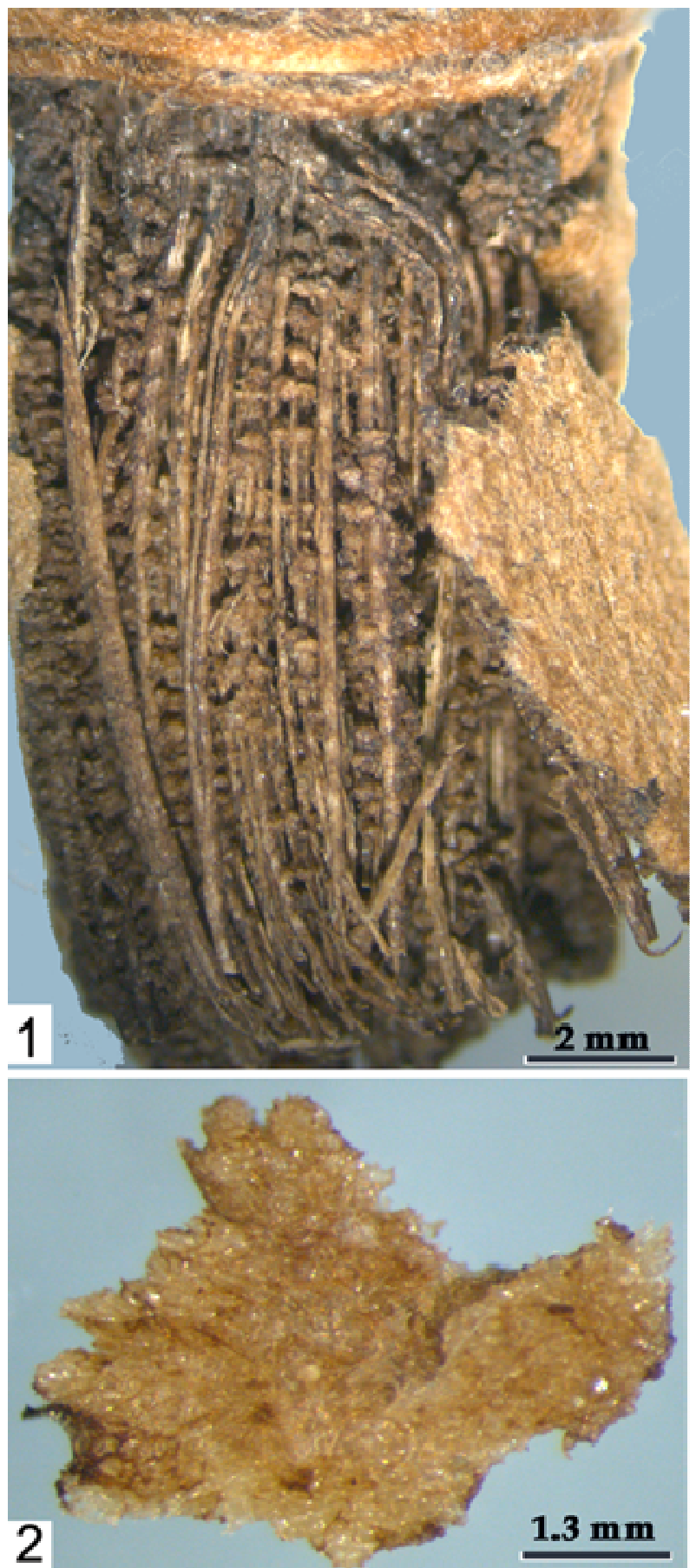

Figure 6. Peduncle showing (1) bunched axes with lateral buds; (2) sclerotic bodies of fused buds at the base.
The branching system thus forms the parastichies of cupules showing thick apophyses with protruding stigmatic arms. The apophyses are distinctly grooved over the cord-like branch ('abaxial suture') that is seen as free axis in the open 'follicles' (Fig. 3 above). Yet 'follicle' is inappropriate designation for a structure no part of which is foliar. The bowls formed by the walls of the filed and lateral arches of adjacent parastichies involve three or four paracladia that are at the same time the 'midribs' of adjacent 'follicles'. The apices of adjacent primary branches adnate and protrude as a stout beak ('style') divided into two recurved arms forming the secondary external stigma or exostigma. A long supple cord-like branch departs from the distal node and curves in a broad arc toward joining the beak of the next paracladium above (Figs. 7, 8).
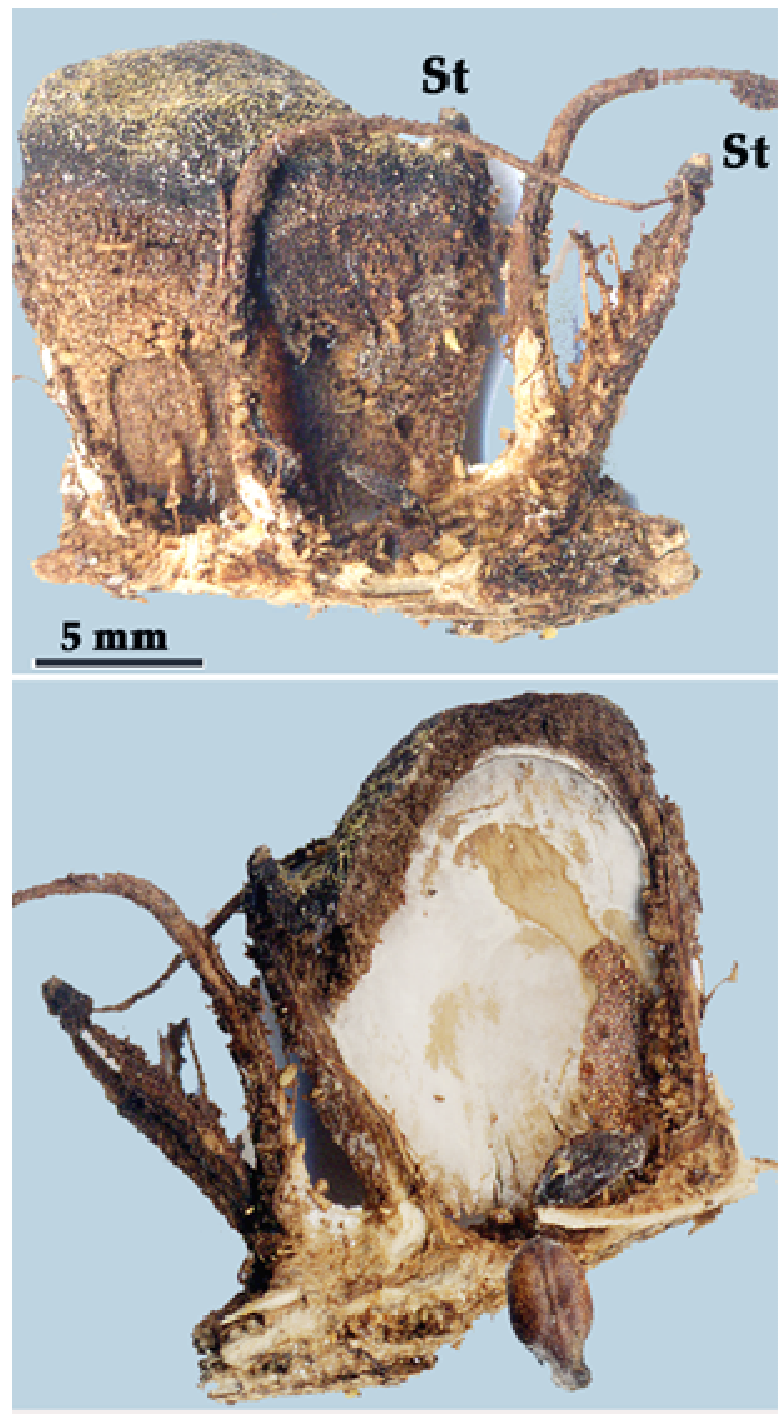

Figure 7. Bowl-shaped cupule seen from outside and inside, with a cord-like offshoot between exostigmatic apices (St) of the supporting primary branches

The interior leathery lining of the bowls ('endocarp') consists of two disconnected crenulate valves covered with a whitish waxy layer, under which there is a pattern of 
overlapping clusters of dense fan-like spreading sclereids betraying a flattened and condensed system of minor branchlets protruding over the margins (Fig. 9).

Branches of all orders are overgrown with sclerotic buds that are compressed into the 'mesocarp' and are flattened into a smooth epidermal layer over the exposed apophyses, but scarcely continued over the lateral contacts. The connecting tissue ('mesocarp') of the woody carcass is formed of palisade rods with apical glands resembling floral nectaries (Fig. 10), suggesting derivation from sclerified floral primordia. The 'trichomes' of exostigmatic arms seem to develop from glandular floral buds as well, capturing pollen grains (Fig. 11).

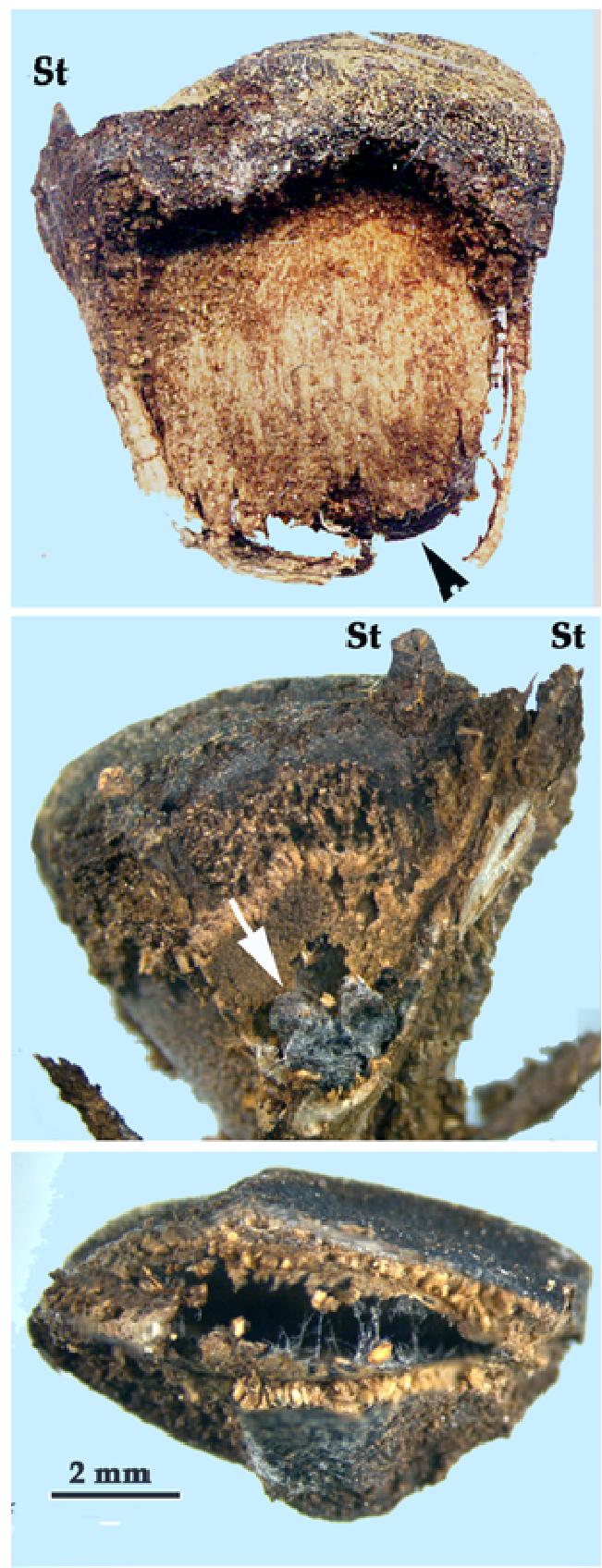

Figure 8. Cupules showing the supporting structures and a cluster of aborted fruits ('seeds') squeezed between them (arrow).

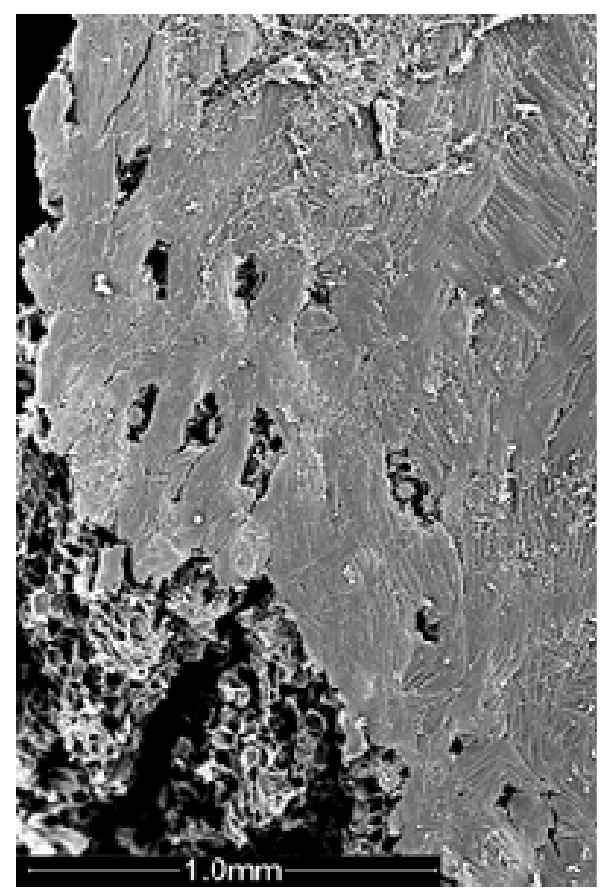

Figure 9. SEM of the cupule inner wall marginally perforated by protruding branchlets, with a pattern of fan-like spreading and overlapping sclerite clusters still discernible
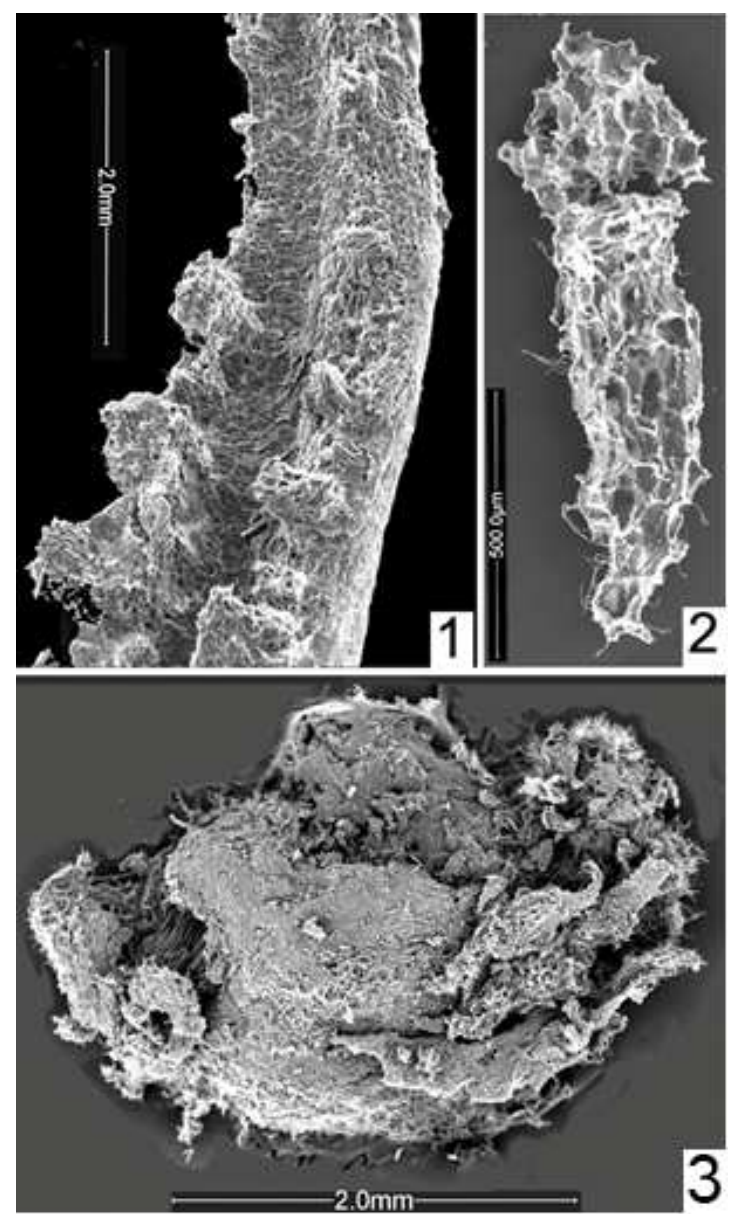

Figure 10. Cupular branch with two rows of sclerified buds (1); rod-like sclerite of connecting tissue with a nectary-like gland on top (2), and an incipient fruiting structure on the main axis (3). 


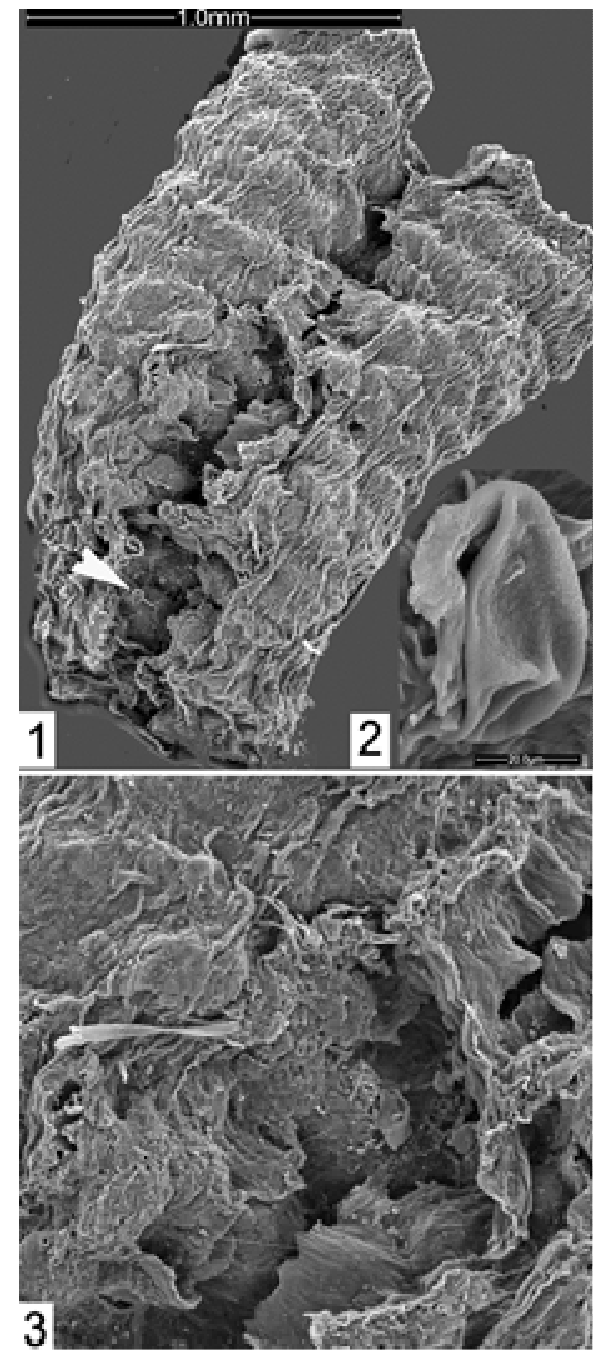

Figure 11. SEM of exostigmatic arm with trichomes supposedly formed of floral buds (1, 3); arrowhead on a germinate pollen grain (2).

The 'seeds' develop in the bowls as well as being squeezed between adjacent paracladia. They are cauliflorous on the main axis or are supported by the sympodial basal ramifications bearing floral buds. Floral parts are occasionally recognizable in minute sclerified buds, ca. 2,5 $\mathrm{mm}$ across, situated in the axils of a prominent spur-like cataphyll (Figs. 12,13), revealing a somewhat zygomorphic perianth of calyptrate petals encasing slender primordial carpels. The protruding carpels are elongate, shortly beaked. The peripheral floral buds are cup-shaped appearing as miniature nectaries. On the main axis, incipient flowers optimistically attempt at blooming in the jungles of cupular branches (Fig. 14). The floral buds may rich ca. $3 \mathrm{~mm}$ wide when petalloid calyptras start to develop into the seed-like bodies. Various stages of this are recorded, from miniature glands as in (Fig. 13N) to gland trusses enswathing the flower (Fig.15-1) to closed calyptras (Figs. 15-2, 18-3).

The glandular layer develops into fleshy 'sarcotesta' at maturity while the thread stretches and winds around the body. The hard wall under the fleshy layer scarcely corresponds to the common idea of seed sclerotesta. It is a smooth ovoid body tapering toward the base (that is where the thread is attached), tube-like flaring at the opposite end, plicate in the upper part. The margin of the tube is lobed or crenulate on one side with sinuses extending as shallow folds down the tube, while deeply cleft on the other side (Figs. 16, 17) betraying a zygomorphic hypanthial structure, with a lampshade sclerified calyx on top. In ripe 'seeds', this is covered with an apical hood of fleshy coat that must be carefully removed in order to expose the persistent floral parts.
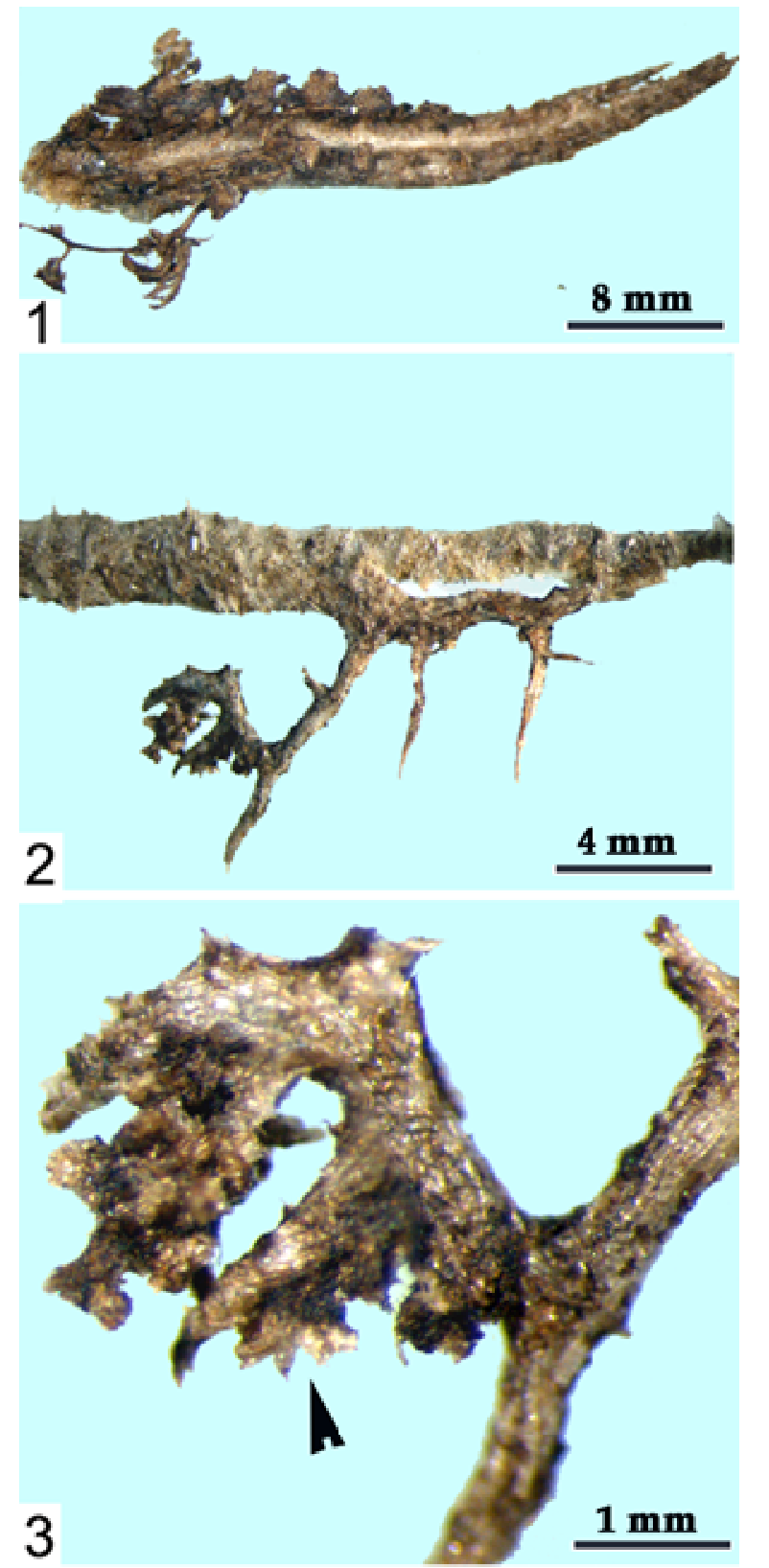

Figure 12. Sclerified floral buds on basal ramifications of a primary branch.

The calyx is about $1.5 \mathrm{~mm}$ wide, rounded-elliptical, radially striate, irregularly lobed, with lobes free or partly coalescent, somewhat revolute over the margin. It is nearly sessile, spread over the stone apex, or raised on a short column with minute appendages or with residual inner cycles that are seldom preserved intact (Fig. 18). The inner cycle 
tepals (petals) protruding from under sessile calyces are broadly triangular up to $2 \mathrm{~mm}$ wide and rather fleshy or smaller and irregular. Those seen under the umbrella of a raised calyx are the innermost petals, crown-like spreading, membranous, wrapping the relatively rigid filaments, apically deflexed (Figs. 19, 20-1).

The interior of the stone is divided by oblique septa into a narrow obconical chamber with residual floral parts and a broad seed locule (Figs. 18-2, 20-2,3). The seed is solitary, inverted on a low caruncle, feeling the locule, thickly cutinized, and producing a rather lavish endosperm. Embryo develops before the walls are hardened, with the relatively massive cotyledons impressed on it.

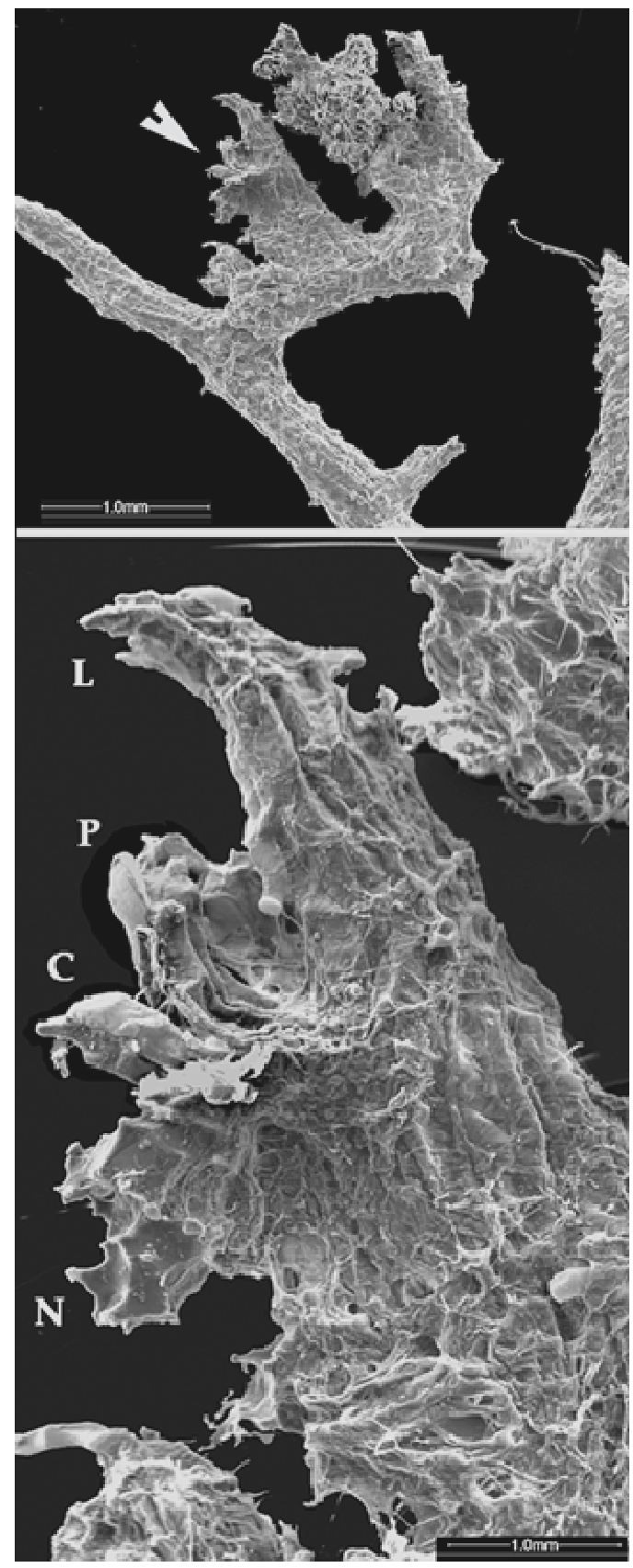

Figure 13. SEM of sclerified floral buds in Fig. 12 (1) and a flower at arrowhead (2) showing cataphyll (L), calyptrate petals (P), primordial carpel $(C)$, and a nectary-like peripheral structure $(N)$.

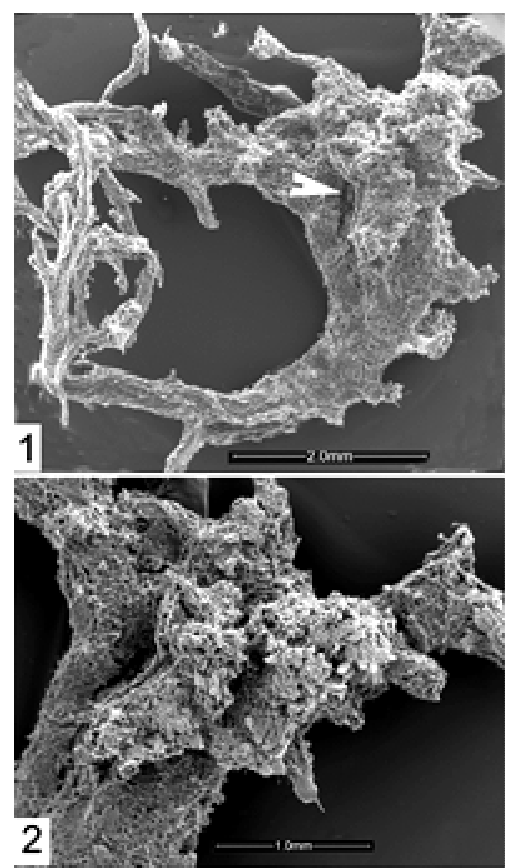

Figure 14. Incipient fruit cluster (arrowhead) in the axil of a ramified cupular branch (1) and blowup showing glandular calyptras (2).
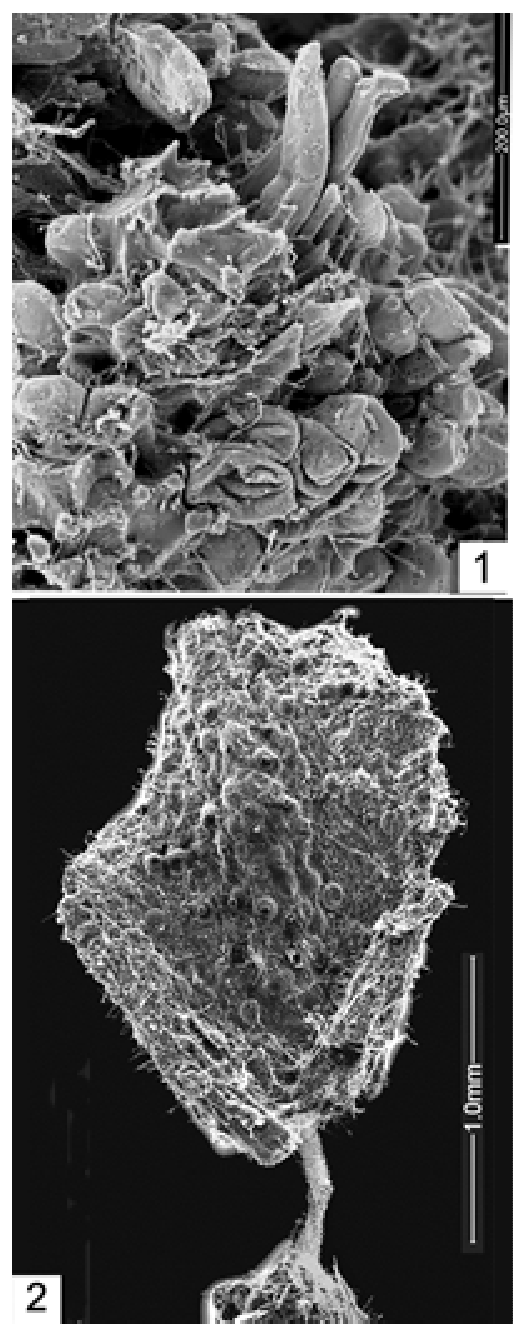

Figure 15. Enswathing of a flower with glandular trusses in the incipient fruit cluster in Fig. 14 (1), developing into young calyptra (2). 


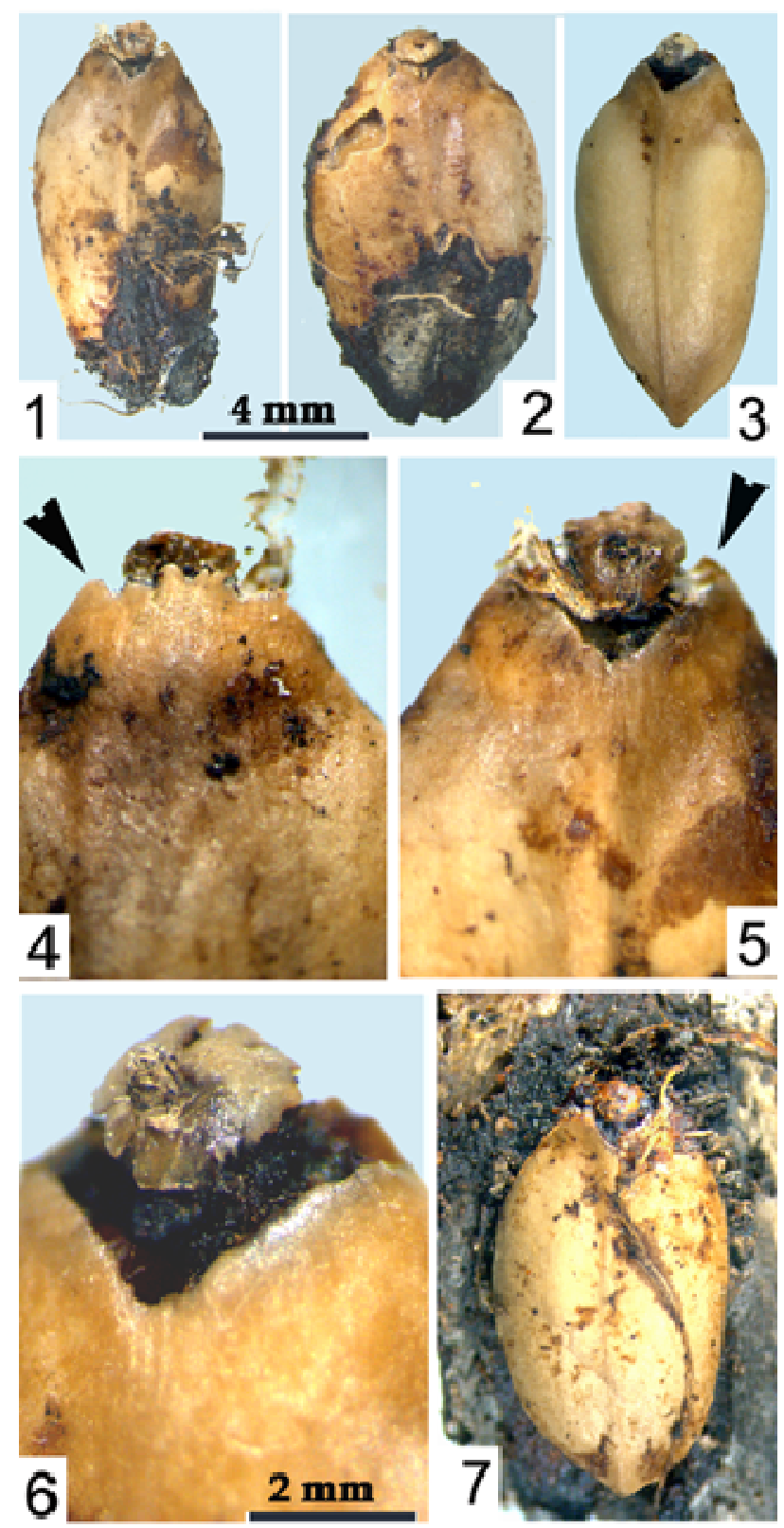

Figure 16. Exposed fruit endocarps formed of corolla tube with a lampshade calyx on top (1-3); zygomorphic corolla tube, posterior and anterior aspects with lobes and a deep median cleave respectively (4, 5); with a well developed calyx lampshade (6); and immersed in the decaying calyptrate epicarp (7).

\section{Discussion}

Our findings suggest that 'flower' of Magnolia grandiflora is at least two orders of magnitude more complex than conventional flower. The gynoecial part of it is a branching system condensed into parastichies of interconnected cupules, the protruding apices of primary branches forming the exostigmatic arms and the connecting cords free in the cupular cavity. No part of this construction is foliar; therefore 'follicle' is inadequate designation. The branching system is immersed in the 'mesocarp' formed of floral buds reduced to clusters of glandular rods. The genuine flowers are minute and inconspicuous, their identity lost in fusion and sclerification, but those developing into fruits retaining rudimentary floral organs encased into glandular calyptras.

Figure 15 shows how the glandular tissue grows over the flower, turning it into a complex 'supergland' conceivably for attracting pollen tubes.

The fruiting structures, traditionally interpreted as seeds, are 'false fruits' or anthocarps, their hard wall composed of corolla tube with calyx and the petal - staminode remains (Figs. 19, 20). These findings imply that also the androecial structures of Magnolia grandiflora must be staminate flowers reduced to solitary stamens, while the showy 'perianth' is formed of inflated staminate or also carpellate structures.
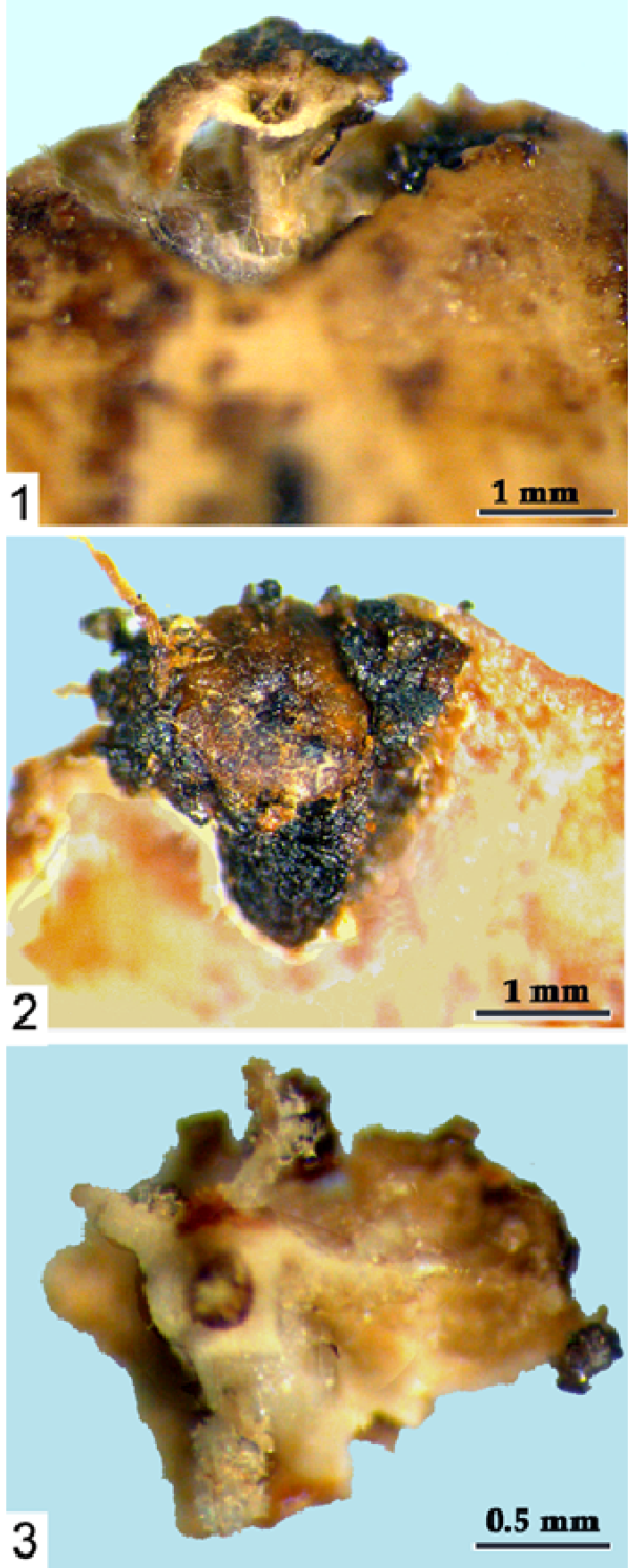

Figure 17. Calyx raised on floral column (1) and sessile, showing petals underneath (2); also seen from inside with appendages on the column (3). 

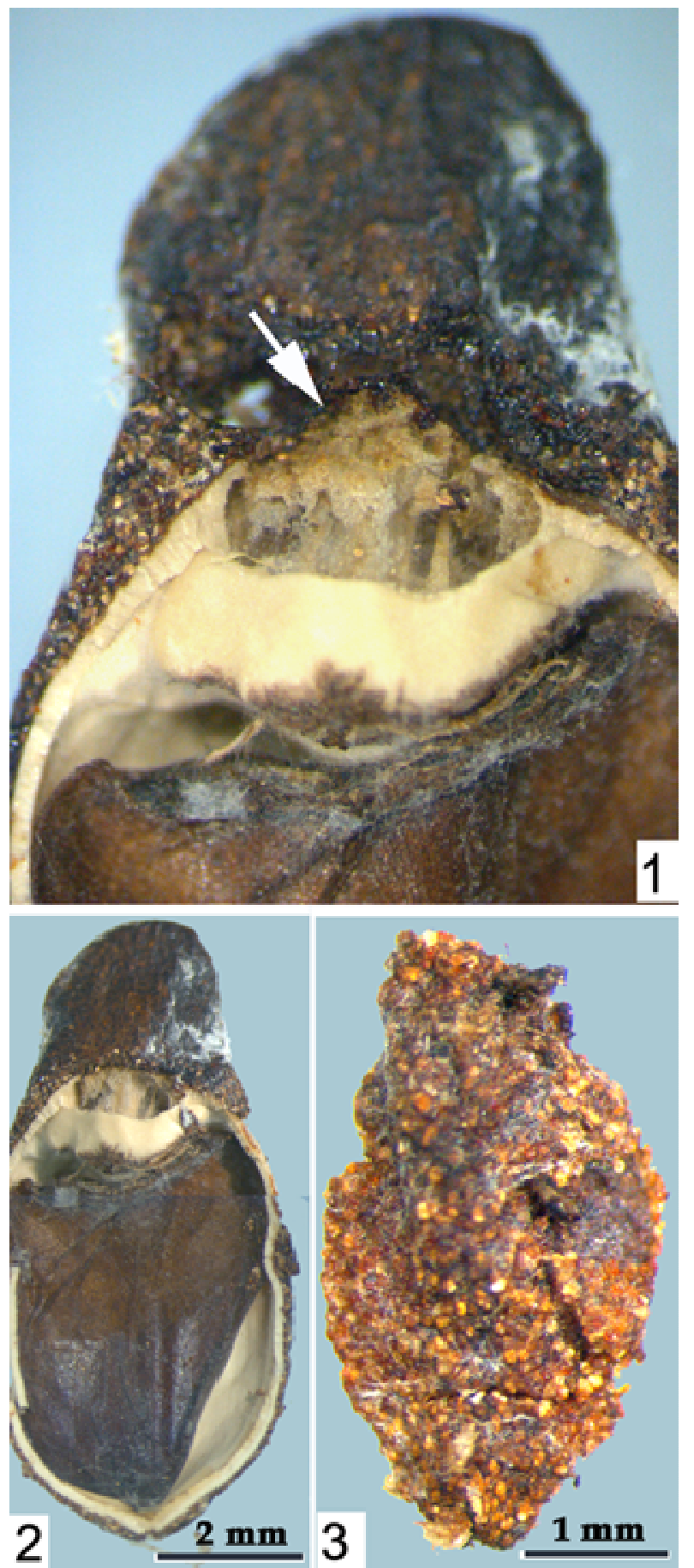

Figure 18. Fruit with the hood partly removed exposing the residual flower at arrow (1,2); developing fruit in glandular calyptra with occasionally emerging branches (3).

Magnolia as here interpreted contradicts the phylogenetic theory of solitary perfect flower being basal for all flowering plants. Neither do they match the characteristics of 'basal angiosperms' 'paleodicots' or whatever, but show highly specialized features with analogues in angiosperm groups usually assigned in advanced 'eudicots'. Thus cupular structures formed of condensed branching systems like acorn cupules (Fig. 2) are characteristic of the Fagaceae, the cupuliferous angiosperms [2, 3], also resembling the euphorbian cyathia with nectar glands on cupular branches and fruit hanging out [4]. The fruit wall is composed of discernible floral parts as in diverse anthocarps [5] the comparable forms of which can be found among the 'hips' of Rosa $[6,7]$, as well as in the Lamiales with a hood-like gavea over persistent flower parts (Lamium) and zygomorphic corolla tubes with calyx on top as in Calceolaria (although scarcely following the agenda of asymmetric two-lipped development [8]).
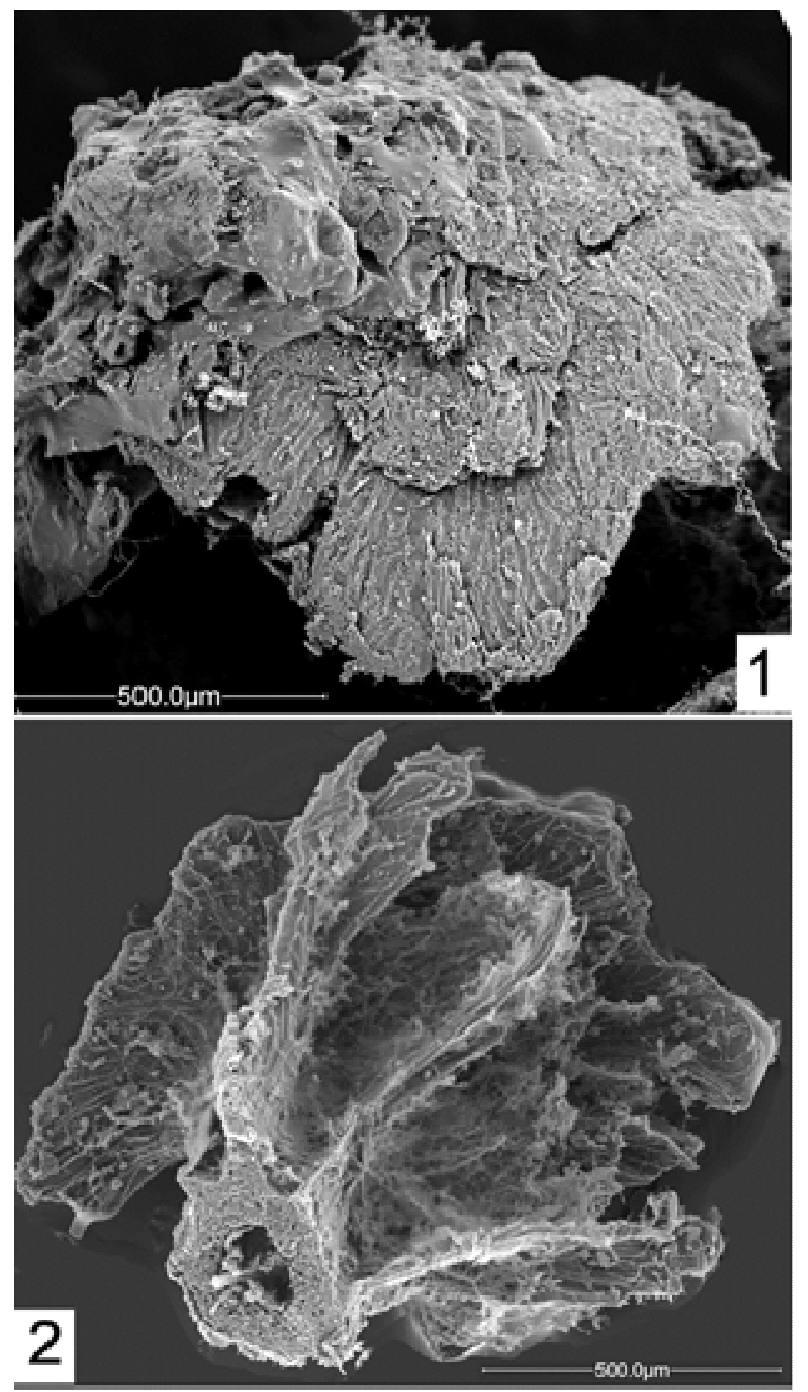

Figure 19. SEM of a lampshade calyx with remains of calyptra on it (1) and the residual flower removed from under the hood in Fig. 18-1, showing membranous petals wrapping around the filaments (2).

These comparisons do not imply that Magnolia is a member of 'eudicots'. Rather they reveal that the paleo/eudicots distinctions scarcely make sense in respect to either extant or extinct diversity of flowering plants. In palynological characteristics Magnolia is closer to monocots than mainstream dicots. But a selected feature is poor evidence of general evolutionary advancement, and palynological characteristics are as good evidence of mosaic evolution as they are poor evidence of phylogenetic relatedness.

'Paleodicots' differ in having monaperturate pollen vs. three 
to polyaperturate in 'eudicots' ([9] and elsewhere). Gymnosperm pollen grains are typically monosulcate. However additional apertures might have simultaneously appeared in various gymnosperm lineages with the loss of bladders over gymnosperm - angiosperm transition and transformation of permanent tetrads into monade pollen grain, with polyaperturate condition fixed in the process of developmental acceleration [10, 11]. Notably, monocolpate pollen is more common in dicots with robust floral parts, those with multiple tiny stamens more often having tricolpate (porate) pollen, thus related to developmental acceleration. As inferred from pollen finds in the guts of fossil insects [12], pollen morphology is a key to pollinator's sensibility, which gives a rationale for morphological convergence as well as divergence in respect to co-evolution bonds.

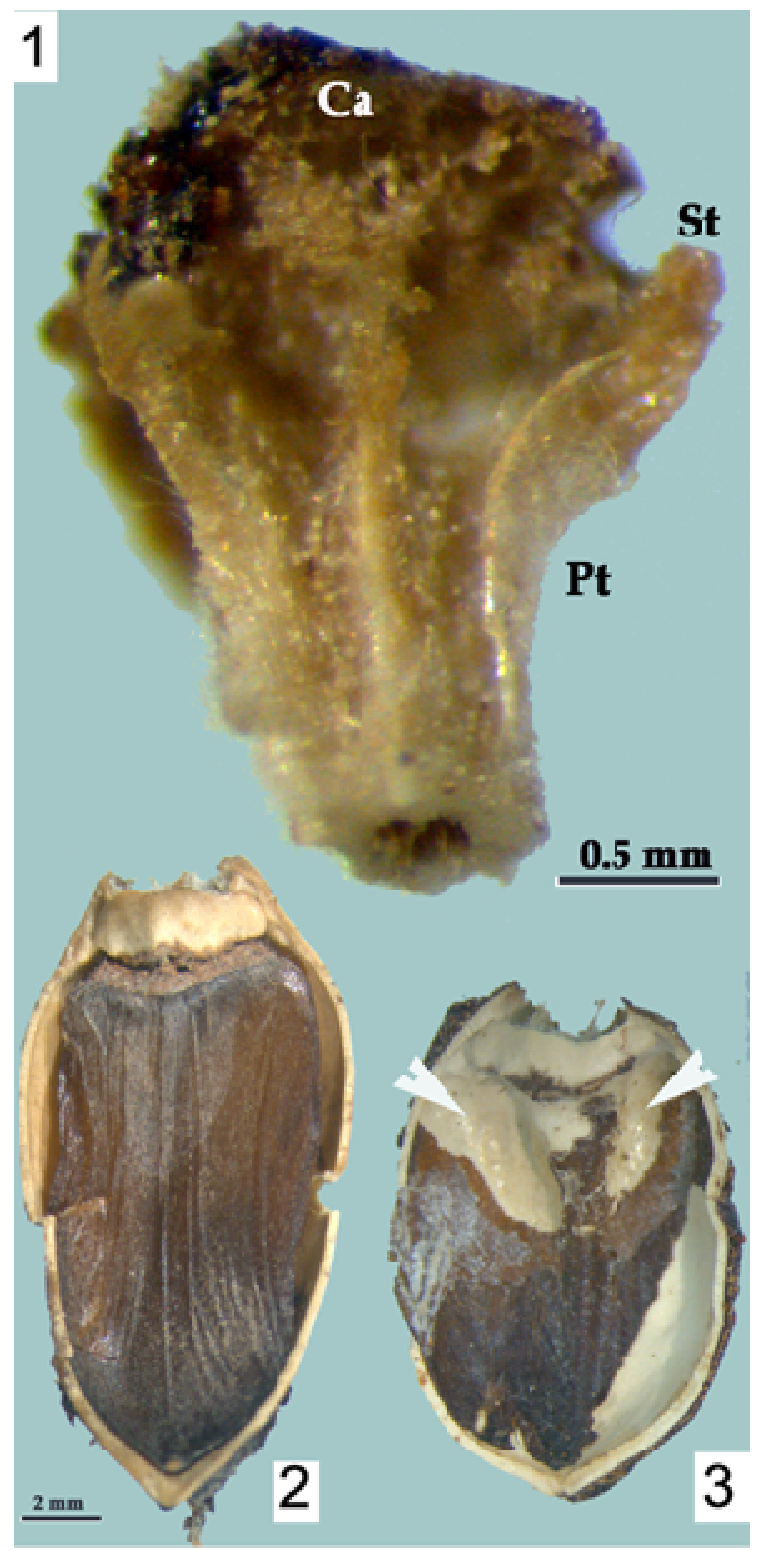

Figure 20. Another aspect of a residual flower seen in Fig. 19-2; C, calyx, P, petals, $S$, filaments (1); split endocarp showing solitary cutinized seed and the basal part of floral chamber above (2), and embryo protruding from under the coalesced testa; Co-cotyledons (3).
Among the retinue of Magnolia grandiflora consorts, microscopic mites appreciate constant humidity of the cupule interiors; beetles seek shelter and pollen proteins; minute fruit flies find juicy pulp; bees are after pollen and sweet excretions; birds flock for bright pendants; and people are fascinated by deceptive beauty of false flowers. Magnolia has to be attractive to them all, but also capable of self-defense by causing allergy with the help of mites. Such functional complexity requires an adequately complex developmental regulation system under the guise of morphological simplicity. When inflorescence looks like flower, fruit like seed, and pollen tetrad like pollen grain it is retroconvergence, caused by regulation system customized to a standard morphology.

In principle, it is for paleobotanists to find out what appeared when and how evolutionary lineages are related. Yet paleobotany could not escape the influence of contemporary pragmatic science philosophy. Because of deliberate distortion and silencing of contradictory facts, the contemporary angiosperm paleobotany is a source of confirmation for whatever phylogenetic paradigm is in vogue. In this spirit, [13] pragmatically invites the reader to notice 'similarity of floral structure' on a picture of extant Magnolia and reconstruction of Archaeanthus, a mid-Cretaceous (late Albian to Cenomanian) fossil of supposed magnoliacean affinities [their Fig. 11.2]. Indeed, a luxurious Magnolia 'perianth' added to the fossil makes it strikingly similar to Magnolia. Mere repetition of such 'arguments' from one compendium to another is a popular means of establishing a paradigm. As an exception, Romanov and Dilcher [14] have made a detailed comparison of fructifications in question and in fact revealed some histological features in common, but scarcely restricted to the magnoliids.

Here evolution is considered to be a telic process of multilevel regulation. The appearance of flowering plants scarcely could have been an occasional happening, but was chronologically as well as causally related to a major renovation of biosphere, in particular the advent of new type 'angiosperm cradle communities' of gnetophytes and other proangiosperms in the middle of the Cretaceous Period [15, 16]. Most prominent among the earliest angiosperms (Aptian - middle Albian, ca. 125 - 108 million years ago; there are no reliable older macrofossils so far) are herbaceous forms akin to the Ranunculaceae, the buttercup family of 'eudicots', including the first microscopically studied middle Albian inflorescence of minute flowers [17] and the first complete flowering plant of approximately the same age [18]. A tiny flower similar to Amborella ('A' in the 'ANITA' grade) has been found in the Cenomanian, ca. 97 MA [19], whereas the oldest though insufficiently preserved Magnolia-like infructescence is Santonian, much later in the Late Cretaceous, but still early, ca. 85 Ma [20). This sequence, albeit preliminary, is incompatible with the currently endorsed schematics of simplified historic relationships.

\section{Conclusion}

This and previous our paper [1] imply that morphology is 
still the major source of new, if but controversial, evidence about nature, revealing factological reality behind the mist of pragmatic mythology and reviving perspective old concepts undeservedly abandoned.

Our interpretation of gynoecial structures in Magnolia being far more complex than a monoaxial polyfollicle represents this charismatic plant in new light, with implications for angiosperm phylogeny not fully explored, but with some vectors, in particular solitary flower $\rightarrow$ inflorescence, likely to be reversed.

Magnolia reveals that simplicity is deceptive. What for many years was perceived as a follicular gynoecium of paradigmatic solitary flower turns out to be a syncopulate structure with exostigmas, delivering seed-like anthocarps. On account of amazing similarity between complex and their constituent simple structures (retroconvergence) 'secondary flower' is a more telling designation than flower-like inflorescence or 'pseudoflower'. Later on one may recognize such structures as 'tertiary flowers' even.

Fascination with simplicity and reduction drive based on it are responsible for replacing historical relationships with cladograms based on superficial morphology, 'molecular clock', etc., with factual evidence habitually neglected. We may, after Darwin, give up fossil record as 'imperfect', which makes evolution groundless, or we may reconsider our demonstrably imperfect concepts of evolution.

\section{Acknowledgements}

We thank Alex Berner and Michael Kalina, the Technion, Haifa for their generous help in SEM studies.

\section{References}

[1] V. Krassilov, and S. Barinova, "Carpel - fruit in a coniferous genus Araucaria and the enigma of angiosperm origin," Journal of Plant Sciences, vol. 2 (5), pp.159-166, 2014.

[2] D. W. Brett, "The inflorescence of Fagus and Castanea and the evolution of the cupules of the Fagaceae," New Phytologist, vol. 63, pp. 90-118, 1964.

[3] L. Forman, "On the evolution of cupules in the Fagaceae," Kew Bull., vol. 118, pp. 385-419, 1966.

[4] G. Prenner, and P. J. Rudall, "Comparative ontogeny of the cyathium in Euphorbia (Euphorbiaceae) and its allies: exploring the organ-flower-inflorescence boundary," Am. J. Bot., vol. 94 (10), pp. 1612-1629, October 2007.

[5] A. B. Bobrov, A. P. Melikyan, and M. C. Romanov, Morphogenesis of carpels in the Magnoliophyta, Moscow, Librocom, 2009, 400 pp. (in Russian).
[6] M. Hickey, and C. King, 100 families of flowering plants, Cambridge Univ. Press, 1988, 619 pp.

[7] V. H. Heywood, Ed., Flowering plants of the world. New York, Oxford University Press, 1993, 335 pp.

[8] E. M. Mayr, and A. Weber, "Calceolariaceae: Floral development and systematic implications," American Journal of Botany, vol. 93(3), pp. 327-343, 2006.

[9] J. A. Doyle, and C. I. Hotton, "Diversification of early angiosperm pollen in a cladistic context," in S. Blackmore, and S. H. Barnes, Eds., Pollen and spores: patterns of diversification, pp. 169-195, Oxford, Clarendon Press, 1991.

[10] V. A. Krassilov, Angiosperm origins: morphological and ecological aspects. Pensoft, Sophia, 1997, 270 pp.

[11] V. Krassilov, "Fossil record of angiosperm origin: new evidence and interpretation," Chapter 2, in Horizons in Earth Science Research, vol. 8, pp. 39-92, New York, Nova Publishers, 2012.

[12] V. A. Krassilov, A. P. Rasnitsyn, and S. A. Afonin, "Pollen eaters and pollen morphology in Paleozoic and Mesozoic plants," Proc. Fossils X 3 Congress, Pretoria. African Invertebrates, vol. 48 (1), pp. 13-22, 2007.

[13] P. S. Soltis, D. E. Soltis, M. W. Chase, P. K. Endres, and P. R. Crane, "The diversification of flowering plants", in J. Cracraft, and M. J. Donoghue, Assembling the tree of life, pp.154-167, Oxford, New York, Oxford Univ. Press, 2004.

[14] M. S. Romanov, and D. L. Dilcher, "Fruit structure in Magnoliaceae s.l. and Archaeanthus and their relationships," American Journal of Botany, vol. 100 (8), pp. 1494-1508, 2013.

[15] V. A. Krassilov, and E. V. Bugdaeva, "An angiosperm cradle community and new proangiosperm taxa," Acta Palaeobot., Suppl. 2, pp. 111-127, 1999.

[16] V. A. Krassilov, and E. V. Bugdaeva, "Gnetophyte assemblage from the Early Cretaceous of Transbaikalia," Palaeontographica, Abt. B, vol. 253, pp. 139-151, 2000.

[17] V. A. Vakhrameev, and V. A. Krassilov, "Reproductive organs of angiosperms from the Albian of Kazakhstan," Palaeontological J. (Moscow), vol. 1, pp. 121-128, 1979. (in Russian).

[18] V. A. Krassilov, and E. B. Volynets, "Weedy Albian angiosperms," Acta Palaeobotanica, vol. 48 (2), pp. 151-169, 2008.

[19] V. A. Krassilov, and L. B. Golovneva, "A minute mid-Cretaceous flower and phylogenetic implications," Geodiversitas, vol. 26 (1), pp. 5-15, 2003.

[20] V. A. Krassilov, Cretaceous flora of Sakhalin, Moscow, Nauka, 1979, 182 pp. (in Russian). 